\title{
Limb-salvage treatment of en-block resected distal femoral tumors with endoprosthesis of all-polyethylene tibial component: a 9-year follow-up study
}

\author{
This article was published in the following Dove Press journal: \\ OncoTargets and Therapy \\ 13 September 2016 \\ Number of times this article has been viewed
}

\author{
Fan Tang \\ Yong Zhou \\ Li Min \\ Wenli Zhang \\ Rui Shi \\ Yi Luo \\ Hong Duan \\ Chongqi Tu \\ Department of Orthopedics, West \\ China Hospital, Sichuan University, \\ Chengdu, People's Republic of China
}

Correspondence: Chongqi Tu Department of Orthopedics, West China Hospital, Sichuan University, Guoxue Xiang \#37, Chengdu, Sichuan 61004I, People's Republic of China

Tel +8618980601387

Fax +8602885423438

Email tcqbonetumor@163.com
Objective: To evaluate the medium-term outcome of limb-salvage surgery using all-polyethylene tibial endoprosthetic replacement following en-block resection for distal femoral tumors.

Methods: Forty-nine patients with distal femoral tumor were treated between June 2006 and June 2012. The follow-up period was 6-110 months (average 53.4 months). The prosthetic survival was analyzed using the Kaplan-Meier method. The classification of failure of limb salvage after reconstructive surgery for bone tumors was adapted. Limb function was evaluated with the scoring system of the Musculoskeletal Tumor Society (MSTS).

Results: Complications were observed in six cases (12.2\%). Four suffered infection around the prosthesis, of which two cases were treated with debridement, drainage, and antibiotics without removal of the prosthesis, and the other two cases underwent amputation. Two cases were identified as radiographically loose at 7 year follow-up and did not require revision surgery. One patient underwent amputation due to local recurrence. Failure of limb salvage occurred in nine cases $(18.4 \%)$, of which two cases were of type $1 \mathrm{~A}$, two cases of type $2 \mathrm{~B}$, three cases of type $4 \mathrm{~A}$, one case of type $4 \mathrm{~B}$, and one case of type $5 \mathrm{~A}$. The mean MSTS score was $84.3 \%$. Twelve cases died due to distant metastases $(24.5 \%)$, and the average survival time for these patients was 13.5 months. Thirty-seven patients survived (75.5\%), for whom the average follow-up time was 66.3 months and the 5-year prosthetic survival rate was $88.2 \%$.

Conclusion: The outcome of medium-term and long-term clinical follow-up was satisfactory. All-polyethylene tibial endoprosthetic replacement following en-block resection can be an alternative method of limb salvage for distal femoral tumors.

Keywords: limb salvage, endoprosthetic replacement, all-polyethylene tibia, distal femur, tumor

\section{Introduction}

Endoprosthetic replacement is a method of reconstruction after limb-salvage resection and is currently the standard treatment for distal femoral tumors. ${ }^{1,2}$ It has the advantages of providing immediate stability, early weight-bearing walking, and long-term good limb function. The prostheses used for the reconstruction of distal femoral defects had undergone three major reforms, from the initial completely restricted knee prosthesis to the use of semi-rotating hinge knee prosthesis, and then the widespread use of rotatinghinge total knee prosthesis in recent years. ${ }^{3,4}$ Recently, most of the rotating-hinge tumor knee prostheses used for reconstruction of distal femoral defects included metal-backed tibial (MBT) components. Although the clinical outcome was satisfactory, ${ }^{5-7}$ there were also some limits with regard to the use of MBT component for tumor knee prostheses. 
The metal bottom bracket and polyethylene gasket have the possibility of dislocation. In addition, the new metal bottom bracket increases the amount of polyethylene gasket wear debris at the interface, which may lead to bone loss. ${ }^{8}$ Also, tumor knee prostheses with MBT components were considered to be expensive. ${ }^{9}$ Another tibial component which was completely made of all-polyethylene was first used in total knee arthroplasty (TKA) and became an acceptable device in 1990s. ${ }^{10}$ Later, many studies regarding the adaptation of allpolyethylene tibial (APT) component in TKA followed. ${ }^{11,12}$ However, reports about the use of APT component in tumor knee prostheses are rare. Tumor knee prostheses differ from conventional TKA in both biomechanics and overall implant survival. ${ }^{13,14}$ In order to understand the clinical performance of tumor knee prostheses with APT components, we retrospectively reviewed patients who accepted APT endoprosthetic reconstruction of the distal femur for tumor resection in our hospital from June 2006 to June 2012.

\section{Methods}

\section{Patients}

Between June 2006 and June 2012, a total of 49 cases with distal femur tumors received limb-salvage surgery using APT endoprosthetic replacement following en-block resection in our institution (Department of Orthopedics, West China Hospital, People's Republic of China). Of the 49 patients,
27 were male and 22 were female (aged 16-65 years; mean 31.4 years). The pathological types included: 25 cases of osteosarcoma, three cases of myofibroblastic sarcoma, two cases of fibrosarcoma, two cases of solitary metastatic carcinoma including one case of breast carcinoma bone metastasis and another of renal carcinoma bone metastasis, two cases of malignant fibrous histiocytoma, one case of malignant mesenchymal cell tumor, ten cases of giant cell tumor, and four cases of giant cell tumor and aneurysmal bone cyst. Pathological fractures occurred in ten out of the 49 cases, of which six cases were of giant cell tumor, three cases of giant cell tumor and aneurysmal bone cyst, and one case of osteosarcoma. Enneking stages were evaluated and included the following: ${ }^{15}$ for malignant bone tumor, one case of stage IA, one case of stage IB, four cases of stage IIA, and 29 cases of stage IIB; for benign bone tumor, five cases of stage II and nine cases of stage III. Chemotherapy was administered in 33 patients. This study was approved by the Institutional Review Board of West China Hospital, Sichuan University, and all patients provided written informed consent in accordance with the Declaration of Helsinki.

\section{Prosthesis}

All the prostheses (Chunlizhengda Medical Instruments Co., Ltd, Beijing, People's Republic of China) were custom-made and had a rotating hinge joint (Figure 1). Both the femoral
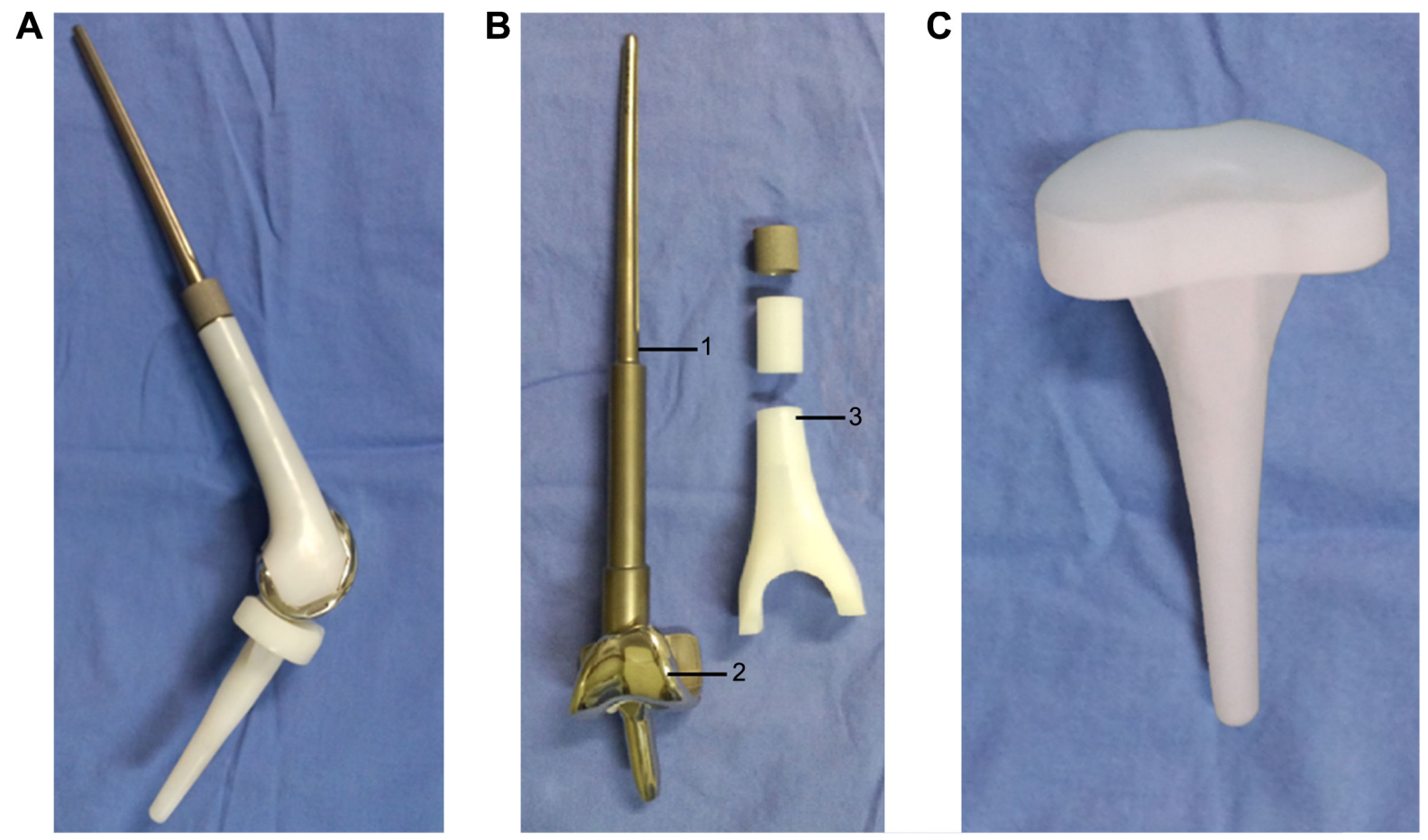

Figure I The prosthesis shown in its entirety, and then as components.

Notes: (A) The APT component prosthesis; (B) I: stem of femoral, 2: femoral condyle, 3: polyethylene surface; (C): the APT component. Abbreviation: APT, polyethylene tibial. 
stem and tibial component were cement type. The prosthesis stem was made of Ti-6Al-4V titanium alloy. The femoral prosthesis coat of a polyethylene plastic prosthesis keeps the shape and volume of the femoral condyle intact, and can reduce the weight of this prosthesis. The femoral condyle was made of $\mathrm{CO}-\mathrm{Cr}-\mathrm{Mo}$ alloy. The tibial component was completely composed of polyethylene material. The prosthesis flexion angle range was $0-150$ degrees and internal or external rotation angle range was $0-12.5$ degrees in extension position. The diameter of the femoral stem was $11-13 \mathrm{~mm}$ and that of the femoral stem terminal was 6-8 mm (approximately half the diameter of the femoral stem). The thickness of the APT component was $12 \mathrm{~mm}$ (Figure 2).

\section{Procedure for tumor resection and reconstruction}

All patients had X-ray and contrast-enhanced magnetic resonance imaging (MRI) of affected limb, computed tomography (CT) of chest, and a radionuclide bone imaging examination preoperatively. Antibiotic bone cement filling was performed after the biopsy. According to the imaging data, measurement parameters for the patients were obtained for creating a customized prosthesis. All operations were performed by the senior surgeon (Chongqi Tu). Wide tumor resection was performed in 39 patients, and marginal tumor resection was performed in ten patients. Extra-articular resection was performed in two patients, and intra-articular resection was performed in 47 patients. The length of the resected femur

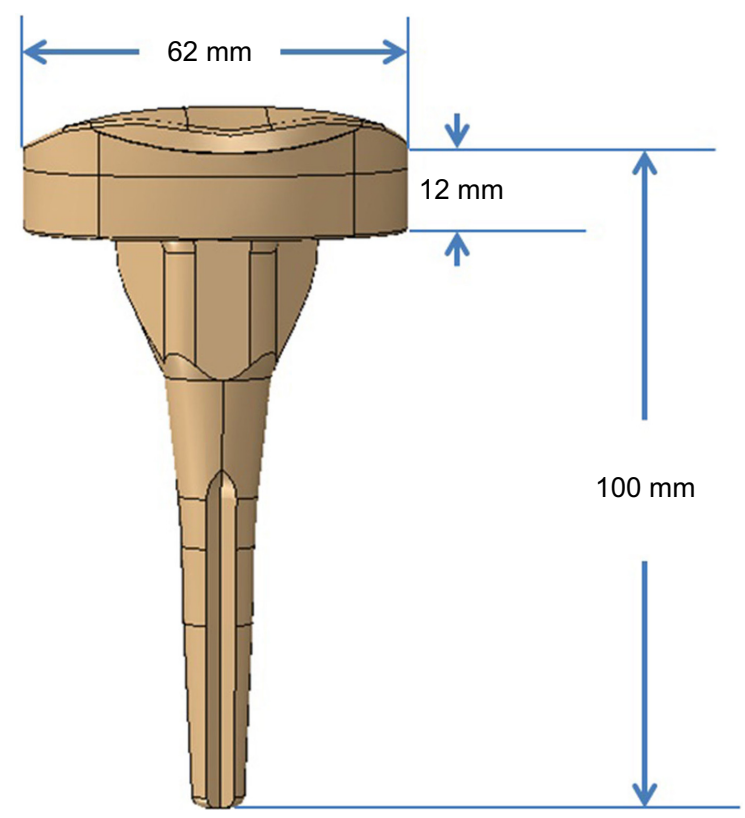

Figure 2 The parameters of the APT component.

Note: The thickness is $\sim 12 \mathrm{~mm}$, and the width can be changed along with the width of the patient's tibial plateau.

Abbreviation: APT, polyethylene tibial. ranged from $7.5 \mathrm{~cm}$ to $28 \mathrm{~cm}$ (average $14.3 \mathrm{~cm}$ ). After resection of the tumor, the bone marrow at the cutting side of femur was taken and an intraoperative biopsy was performed to ensure complete resection has been achieved with no tumor invasion. More than three segments of the quadriceps femoris muscle was resected in two patients. All patients used APT components at tibial side. Femoral stem and tibial component were fixed with gentamicin bone cement $\left(\mathrm{CMW}^{\circledR}\right.$; Depuy International Ltd., Leeds, UK). Three patients needed local musculocutaneous flap to cover the defects in the soft tissue and skin after prosthetic reconstruction. Popliteal lymph node dissection was performed in 37 cases during tumor resection procedure, and these lymph nodes were sent for biopsy to ensure that metastasis had not occurred.

\section{Statistical analysis}

All patients were followed up for a period of 6-110 months (average 53.4 months). Prosthetic survival rate, knee function, and oncological results were evaluated. SPSS 22.0 software (IBM Corporation, Armonk, NY, USA) was used for the statistical processing of the data. The prosthetic survival rate was calculated as the time from surgical reconstruction, using tumor knee prostheses of polyethylene tibia, to prosthetic failure, and cases that died were not included for prosthetic survival evaluation. Prosthetic failure was defined as aseptic loosening, periprosthesis fracture, dislocation, breakage, and amputation due to infection and recurrence. The International Society of Limb Salvage system (ISOLS) classification of failure of limb salvage after endoprosthetic reconstruction was adapted. ${ }^{16}$ Survival curves were constructed using the Kaplan-Meier method. Patients were censored from statistical analysis (observation stopped before the event occurred) if their endoprosthesis had not failed by the time of their last assessment. The log-rank test was performed to compare the survival of the patients. A value of $P<0.05$ was considered to be significant in all statistical analyses. The Musculoskeletal Tumor Society (MSTS) scoring system was applied to evaluate the limb function. ${ }^{17}$

\section{Results}

Twelve cases died due to distant metastases (24.5\%), and the average survival time for these cases was 13.5 months. Thirty-seven patients survived (75.5\%), of which 35 cases survived without tumors. The average follow-up time for 37 survival cases was 66.3 months. Local recurrence occurred in three cases $(6.1 \%)$, including two cases that were treated with local excision and showed no tumor recurrence at their last follow-up, and the remaining one case ended up 

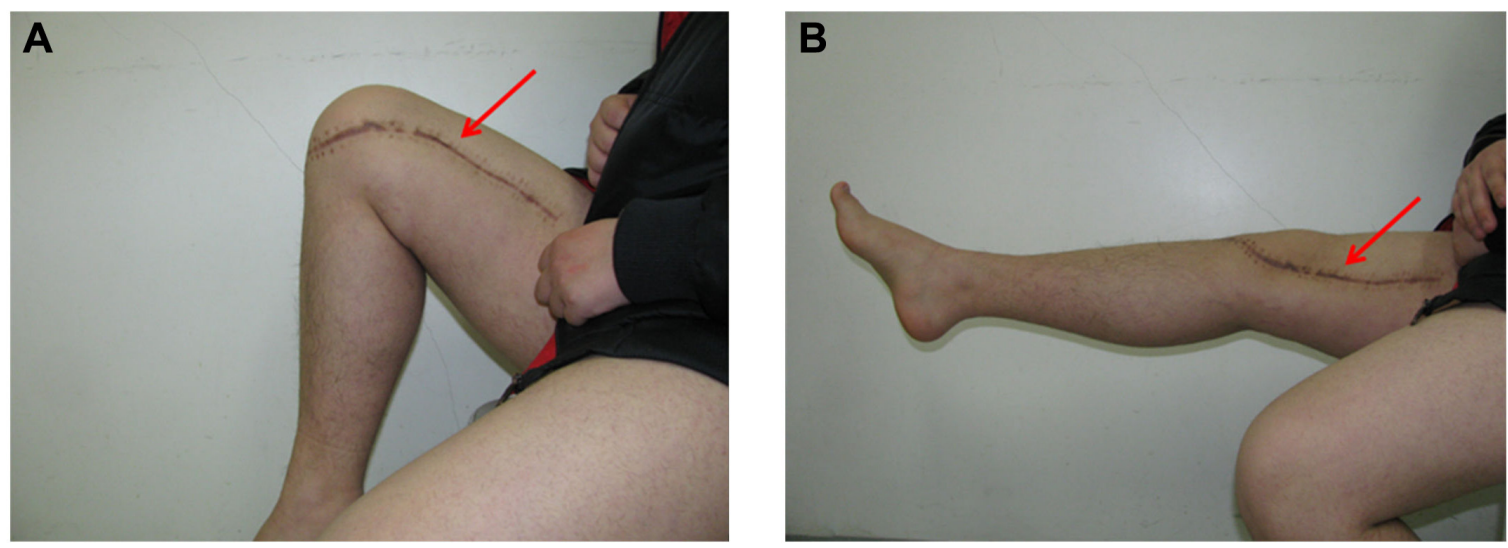

Figure 3 Good knee function after surgery.

Notes: The patient will be able to achieve 90 degrees flexion $(\mathbf{A})$ and close to 0 degree extension (B). The arrows indicate the medial curved incision made during surgery.

with amputation. Limb flexion and extension function was evaluated at 6-12 months after surgery. Except for two patients who had a large resection of more than three segments of the quadriceps femoris muscle and knee extension of only -20 degrees, all patients were able to reach close to 0 degrees extension (Figure 3). The average MSTS score was $84.3 \% \pm 8.53 \%$.

Complications were observed in six cases (12.2\%). Four suffered from periprosthetic infection, of which three cases occurred within the initial 2-year postoperative period and one case occurred after the initial 2-year postoperative period. The median time to infection in our study was 13.5 months. Among the four infection cases, two cases were treated with debridement, drainage, and antibiotics without removal of the prosthesis, and in the other two cases, amputation occurred. Two prostheses were identified as radiographically loose on femoral side at 7 years follow-up; as the radiolucent lines around the femoral stem were stable over the years, prostheses did not require a revision in the near future. Failure of limb salvage after endoprosthetic reconstruction occurred in nine cases (18.4\%), of which two cases were of type 1A, two cases of type $2 \mathrm{~B}$, three cases of type $4 \mathrm{~A}$, one case of type $4 \mathrm{~B}$, and one case of type $5 \mathrm{~A}$ (Table 1). No events of stem breakage, dislocation, or periprosthetic fracture were observed (Figure 4). For the 37 survival cases, the 5-year overall prosthetic survival rate was $88.2 \%$ (Figure 5 ). The log-rank

Table I Details of patients who suffered failure of limb salvage after all-polyethylene tibial endoprosthetic replacement

\begin{tabular}{|c|c|c|c|c|c|c|c|c|c|}
\hline Case & $\begin{array}{l}\text { Age, } \\
\text { years/sex }\end{array}$ & $\begin{array}{l}\text { Primary } \\
\text { tumor }\end{array}$ & $\begin{array}{l}\text { Failure } \\
\text { classification }\end{array}$ & $\begin{array}{l}\text { Chemotherapy } \\
(\mathrm{Y} / \mathrm{N})\end{array}$ & $\begin{array}{l}\text { Resection } \\
\text { type (I/E) }\end{array}$ & $\begin{array}{l}\text { Resection } \\
\text { length }(\mathrm{cm})\end{array}$ & $\begin{array}{l}\text { Quadriceps } \\
\text { femoral } \\
\text { resected (n) }\end{array}$ & Treatment & Final result \\
\hline I & $2 \mathrm{I} / \mathrm{M}$ & Osteosarcoma & Type IA & $Y$ & I & 16 & 3 & $\begin{array}{l}\text { Moderate } \\
\text { movement of limbs }\end{array}$ & $\begin{array}{l}\text { Function } \\
\text { steady }\end{array}$ \\
\hline 2 & $46 / F$ & MFH & Type IA & $Y$ & $\mathrm{E}$ & 21 & 3 & $\begin{array}{l}\text { Moderate } \\
\text { movement of limbs }\end{array}$ & $\begin{array}{l}\text { Function } \\
\text { steady }\end{array}$ \\
\hline 3 & $45 / M$ & $\mathrm{GCT}+\mathrm{ABC}$ & Type 2B & $\mathrm{N}$ & I & 15 & 0 & $\begin{array}{l}\text { Continuous } \\
\text { observation }\end{array}$ & $\begin{array}{l}\text { Does not } \\
\text { need revision }\end{array}$ \\
\hline 4 & $16 / M$ & Osteosarcoma & Type 2B & $Y$ & I & 19 & I & $\begin{array}{l}\text { Continuous } \\
\text { observation }\end{array}$ & $\begin{array}{l}\text { Does not } \\
\text { need revision }\end{array}$ \\
\hline 5 & $20 / F$ & Osteosarcoma & Type 4A & $Y$ & I & 17 & I & $\begin{array}{l}\text { Debridement + } \\
\text { antibiotics }\end{array}$ & Local control \\
\hline 6 & $27 / M$ & Osteosarcoma & Type 4A & $Y$ & 1 & 14 & 2 & $\begin{array}{l}\text { Debridement + } \\
\text { antibiotics }\end{array}$ & Amputation \\
\hline 7 & $2 \mathrm{I} / \mathrm{M}$ & Osteosarcoma & Type 4A & $Y$ & I & 18 & I & $\begin{array}{l}\text { Debridement + } \\
\text { antibiotics }\end{array}$ & Local control \\
\hline 8 & $50 / \mathrm{M}$ & $\mathrm{GCT}+\mathrm{ABC}$ & Type 4B & $\mathrm{N}$ & I & 13 & 0 & $\begin{array}{l}\text { Debridement + } \\
\text { antibiotics }\end{array}$ & Amputation \\
\hline 9 & $28 / F$ & $\begin{array}{l}\text { Myofibroblastic } \\
\text { sarcoma }\end{array}$ & Type 5A & $Y$ & I & 16 & 0 & $\begin{array}{l}\text { Antibiotics + } \\
\text { surgery }\end{array}$ & Amputation \\
\hline
\end{tabular}

Abbreviations: MFH, malignant fibrous histiocytoma; GCT, giant cell tumor; ABC, aneurysmal bone cyst; I, interarticular; E, extra-articular; Y, yes; N, no; F, female; M, male. 

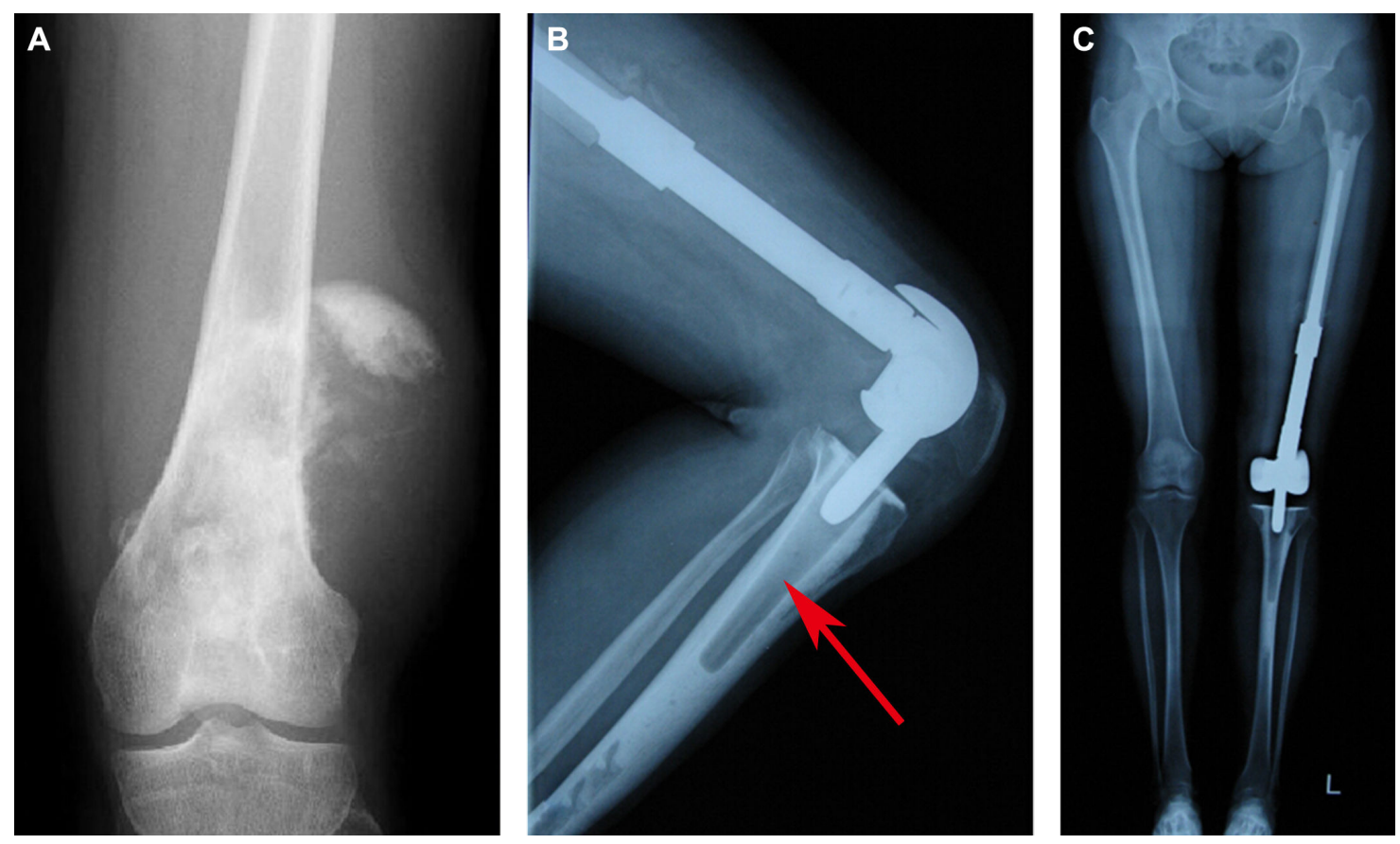

Figure 4 X-ray of patient with osteosarcoma of the left distal femur treated with all-polyethylene tibial endoprosthetic replacement.

Notes: (A) Preoperative X-ray; (B) postoperative X-ray at flexed position. The arrow indicates that the tibia component is not visible in X-ray because it is completely made of polyethylene; $(\mathbf{C})$ postoperative $\mathrm{X}$-ray of lower extremity suggests a good length and strength line.

test showed no statistical differences between the prosthetic survival rate and the patient characteristics (Table 2).

\section{Discussion}

All the prostheses used in this study were custom-made to fit the Asian body type. Based on our clinical experience, we assumed that changing the tibial component from "polyethylene gasket + metal carrier" to "all-polyethylene material" would be associated with some advantages.

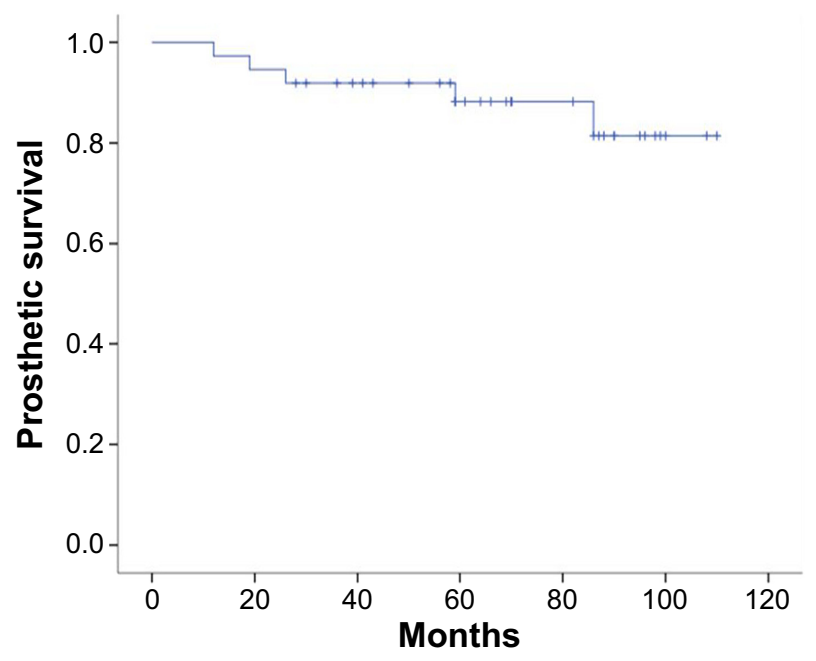

Figure $\mathbf{5}$ The Kaplan-Meier curve shows overall prosthetic survival rate for the 37 alive patients.
First, the integrated design of APT component is convenient to remove when revising. Moreover, some studies have reported that APT components have a lower risk of early revision than metal-backed modular components. ${ }^{18,19}$ Second, polyethylene of APT component prosthesis is more thicker than MBT component prosthesis, thus APT prostheses can

Table 2 The relationship between prosthetic survival rate and patient characteristics

\begin{tabular}{llll}
\hline Factors & $\mathbf{n}$ & $\begin{array}{l}\text { 5-year } \\
\text { survival (\%) }\end{array}$ & P-value \\
\hline Age & & & 0.281 \\
$\quad \geq 25$ years & 25 & 92.0 & \\
$\quad<25$ years & 12 & 61.1 & 0.121 \\
Sex & & & \\
$\quad$ Male & 18 & 83.3 & 0.104 \\
$\quad$ Female & 19 & 93.3 & \\
Tumor character & & & \\
$\quad$ Malignant & 23 & 79.1 & 0.082 \\
$\quad$ Benign & 14 & 91.7 & \\
Chemotherapy & & & 0.428 \\
$\quad$ Yes & 22 & 77.7 & \\
$\quad$ No & 15 & 91.7 & 0.915 \\
Resection length & & & \\
$\quad \geq 14 \mathrm{~cm}$ & 23 & 85.6 & \\
$\quad<14 \mathrm{~cm}$ & 14 & 92.9 & \\
Stem diameter & & & \\
$\quad \geq 12$ mm & 17 & 88.2 & \\
$\quad<12$ mm & 20 & 88.7 & \\
\hline
\end{tabular}


with stand heavier wear and are more durable. In addition, APT components can reduce the weight of the prosthesis and were sometimes considered as a cost-saving technique. ${ }^{9}$ In fact, it is cheaper than MBT component tumor knee prostheses in our department. The cost of an APT component tumor knee prosthesis is $\sim$ US $\$ 5,600$, whereas the cost of an MBT component tumor knee prosthesis is roughly $\sim$ US $\$ 7,400$ in our department. The cost of an imported third-generation tumor knee prosthesis manufactured by Stryker Corporation (Kalamazoo, MI, USA) is US $\$ 14,600$ in the People's Republic of China, and the cost varies with respect to the stem length/type. APT components generate higher stress and micromotions than MBT components in TKA; ${ }^{20}$ however, whether the same phenomenon is observed in tumor knee prosthetic reconstruction is unknown. Because long distal femoral defects need reconstruction, tumor knee endoprosthetic replacement differs from conventional TKA in biomechanics; hence, further biomechanical analysis was needed for improvement of the prostheses.

The 5-year prosthetic survival rate of $88.2 \%$ was observed in our study and the reasons for failure were mainly infection, aseptic loosening, and tumor progression. Although it is difficult to directly compare the survival results of the current study to those of the previous studies because of differences in the tibial components, heterogeneity, and differences in the lifestyle of the patient population, our result is generally in keeping with the findings of most reports published in the literature (Table 3). ${ }^{21-24}$ But our study had some limitations: 1) due to few positive-result cases in our study, there was no statistically significant difference in comparative analysis of patients characteristic for prosthetic survival rate; and 2) extra-articular resection was rarely performed in our study, so it was not possible to draw meaningful conclusions as to whether this subgroup was at any risk in terms of infection, loosening, and stem breakage. So, for further clinical outcome studies, more number of cases and longer term follow-up period are needed.

The rate of infection, which was the main complication in our study, was $10.8 \%$ (4/37), including two cases of infection after implant survival and two cases of invalid amputation. The median time to infection in our study was 13.5 months, of which three cases occurred within 2 years and one case 2 years after original operation. Chemotherapy is one of the causative factors of early infection. ${ }^{25}$ The immunosuppression caused by chemotherapy in patients who receive drugs, extensive resection of bone and soft tissues, and longer operative time for the resection of the tumor increase the risk of infection in primary treated patients. ${ }^{26,27}$ There were

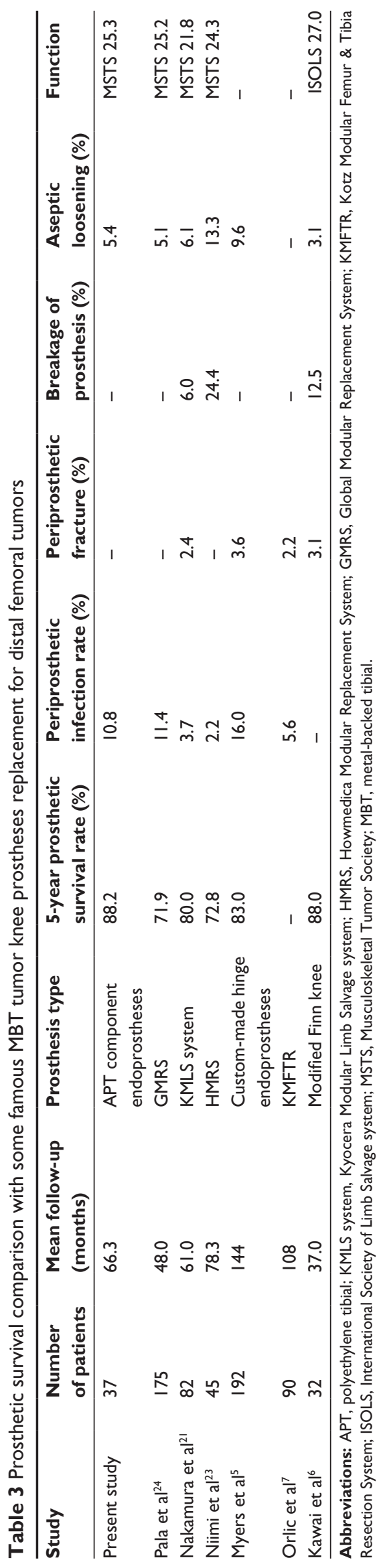


two cases of infection during chemotherapy in our study, but due to limited number of cases, the result seemed to have no statistical significance. There was a high incidence of late infections that developed quite spontaneously without apparent cause many years after the original limb-salvage operation. When adjuvant chemotherapy is needed after prosthetic reconstruction, preventive antibiotics may be required during chemotherapy. ${ }^{28}$ Furthermore, providing adequate soft tissue coverage after reconstruction is one of the most critical factors for reducing infection. ${ }^{21}$ Insufficient muscle coverage of the implant can be improved with free muscle flap or vascularized muscle transfer. Finally, sufficient assessment of tumor boundary before surgery and improvement of surgical skills may help shorten the operation time and consequently decrease the infection risk.

In our study, two prostheses (5.4\%) were identified as radiographically loose at 7 years follow-up. As the radiolucent lines around the femoral stem were stable over the years, the prostheses did not require a revision surgery in the near future. Aseptic loosening remains a major problem after prosthetic replacement of large bone defects according to some studies. ${ }^{21,23}$ Conventional aseptic loosening manifests as osteoclast-mediated periprosthetic resorption of bone, and this might occur due to the accumulation of microscopic polyethylene debris due to wear at the interface between metal bottom bracket and polyethylene, which usually presents several years after original reconstruction surgery. ${ }^{29}$ Poor cementing technique may also play a role in aseptic loosening. Early aseptic loosening may result from poor bone growth or from the formation of a fibrous bone-implant junction in patients undergoing adjuvant chemotherapy for malignant bone tumor. ${ }^{30,31}$ The stress dispersion at the interface between cement and polyethylene in APT component and cement and metal in MBT component may be different, which can result in loosening of the APT component. But none of the two aseptic loosening cases in this study occurred due to APT component failure. This result suggests that APT component showed good fixation with bone cement in distal femoral defects reconstruction. In our study, the two aseptic loosening cases might have occurred due to poor cementing fixation technique used.

Amputation following prosthetic replacement was required in three patients $(8.1 \%)$ in our study, including two cases of prosthesis infection and one case of local recurrence. The risk of a patient requiring amputation is related to the rate of local recurrence as well as the risk of deep infection. ${ }^{32}$ The rate of local recurrence is inevitably associated with a reduction of surgical margins. ${ }^{33}$ For patients with large tumors, only a marginal excision can be achieved, but has not been shown to lead to any improved overall survival. Under these circumstances, the surgeon should discuss with the patient about the risks and benefits of limb-salvage surgery compared with amputation. Sometimes, enlarged popliteal fossa lymph nodes were noticed when distal femoral tumors exhibited high degree of malignancy or were of huge volume. Most of these enlarged lymph nodes were due to reactive hyperplasia and a few were due to cancer metastasis, but it is difficult to distinguish between them at the time of operation. So, we performed popliteal lymph nodes dissection during the tumor resection procedure in primary surgery to decrease the local recurrence rate.

Good limb function can improve emotional acceptance. Previous studies on patients with 3-10 years of follow-up reported an MSTS score of $72 \%-90 \%$, and the score level was mainly associated with pathological fractures, prosthesis design, reconstruction surgery, and prosthesis-related complications. ${ }^{19-21}$ Limited function owing to insufficient musculoligamentous attachment is classified as failure of function (type 1A) according to the latest ISOLS classification guidelines. ${ }^{16}$ Excessive soft tissue resection, tendon rupture, and poor soft tissue growth into the prosthesis may lead to dysfunction. In our study, more than three segments of the quadriceps femoris muscle was resected in two patients and their function score was quite low. So, reconstruction of the knee-stretching device sometimes becomes necessary.

In the follow-up period, there was no stem breakage, prosthesis dislocation, or periprosthetic osseous fracture. In our opinion, the main strength of our study is that all the patients had been treated at the same institution by the same team of surgeons, so the operation skills may have little difference in all patients. Good strength line was also observed in most patients (Figure 4). Furthermore, the integrated design of APT component can avoid dislocation at tibial side. Few studies about MBT prostheses have reported that the fracture rate of the basal part of knee tumor prosthesis was $8 \%$ and that the material had fatigue cracking and limits of endurance. ${ }^{5}$ Other researchers suggested that the mechanical source of distal femoral endoprosthetic failure has most commonly been the femoral stem, as the junction of the prosthesis stem and the bone stem can easily break, which can be considered due to stress concentration in this part. ${ }^{6,21}$

\section{Conclusion}

The outcome of medium-term and long-term clinical follow-up is promising. From the view of clinical application, the APT component in tumor knee prosthesis is of potential 
benefit in limb-salvage surgery, and APT endoprosthetic replacement can be an alternative method of limb salvage for distal femoral tumors. Meanwhile, more cases, longer term follow-up period, and further evidence on biomechanics are needed to improve the performance.

\section{Disclosure}

The authors report no conflicts of interest in this work.

\section{References}

1. Xu S, Yu X, Xu M, et al. Limb function and quality of life after various reconstruction methods according to tumor location following resection of osteosarcoma in distal femur. BMC Musculoskelet Disord. 2014; $15: 453$.

2. Henderson ER, Pepper AM, Marulanda G, Binitie OT, Cheong D, Letson GD. Outcome of lower limb preservation with an expandable endoprosthesis after bone tumor resection in children. $J$ Bone Joint Surg Am. 2012;94(6):537-547.

3. Grimer RJ, Carter SR, Tillman RM, et al. Endoprosthetic replacement of the proximal tibia. J Bone Joint Surg Br. 1999;81(3):488-494.

4. Mavrogenis AF, Pala E, Angelini A, et al. Infected prostheses after lower-extremity bone tumor resection: clinical outcomes of 100 patients. Surg Infect (Larchmt). 2015;16(3):267-275.

5. Myers GJ, Abudu AT, Carter SR, Tillman RM, Grimer RJ. Endoprosthetic replacement of the distal femur for bone tumours: long-term results. J Bone Joint Surg Br. 2007;89(4):521-526.

6. Kawai A, Healey JH, Boland PJ, Athanasian EA, Jeon DG. A rotatinghinge knee replacement for malignant tumors of the femur and tibia. J Arthroplasty. 1999;14(2):187-196.

7. Orlic D, Smerdelj M, Kolundzic R, Bergovec M. Lower limb salvage surgery: modular endoprosthesis in bone tumour treatment. Int Orthop. 2006;30(6):458-464.

8. Rouanet T, Combes A, Migaud H, Pasquier G. Do bone loss and reconstruction procedures differ atrevision of cemented unicompartmental kneeprostheses according to the use of metal-back or all-polyethylene tibial component? Orthop Traumatol Surg Res. 2013;99(6):687-692.

9. Pomeroy DL, Schaper LA, Badenhausen WE, et al. Results of allpolyethylene tibial components as a cost-saving technique. Clin Orthop Relat Res. 2000;(380):140-143.

10. Apel DM, Tozzi JM, Dorr LD. Clinical comparison of all polyethylene and metal backed tibial components in total knee arthroplasty. Clin Orthop Relat Res. 1991;273:243-252.

11. Shen B, Yang J, Zhou Z, Kang P, Wang L, Pei F. Survivorship comparison of all-polyethylene and metal-backed tibial components in cruciate-substituting total knee arthroplasty - Chinese experience. Int Orthop. 2009;33(5):1243-1247.

12. Nouta KA, Pijls BG, Nelissen RG. All-polyethylene tibial components in TKA in rheumatoid arthritis: a 25-year follow-up study. Int Orthop. 2012;36(3):565-570.

13. Crosby SN, Polkowski GG, Schwartz HS, Shinar AA, Holt GE. Metalbacked versus all-polyethylene tibias in megaprostheses of the distal femur. J Arthroplasty. 2011;26(3):451-457.

14. Cheng T, Zhang G, Zhang X. Metal-backed versus all-polyethylene tibial components in primary total knee arthroplasty. Acta Orthop. 2011; 82(5):589-595.

15. Enneking WF, Spanier SS, Goodman MA. A system for the surgical staging of musculoskeletal sarcoma. Clin Orthop Relat Res. 1980;153: $106-120$.
16. Henderson ER, O'Connor MI, Ruggieri P, et al. Classification of failure of limb salvage after reconstructive surgery for bone tumours: a modified system including biological and expandable reconstructions. Bone Joint J. 2014;96-B(11):1436-1440.

17. Enneking WF, Dunham W, Gebhardt MC, Malawar M, Pritchard DJ. A system for the functional evaluation of reconstructive procedures after surgical treatment of tumors of the musculoskeletal system. Clin Orthop Relat Res. 1993;286:241-246.

18. Mohan V, Inacio MC, Namba RS, Sheth D, Paxton EW. Monoblock all-polyethylene tibial components have a lower risk of early revision than metal-backed modular components. Acta Orthop. 2013;84(6): 530-536.

19. Pala E, Mavrogenis AF, Angelini A, Henderson ER, Douglas Letson G, Ruggieri P. Cemented versus cementless endoprostheses for lower limb salvage surgery. J BUON. 2013;18(2):496-503.

20. Brihault J, Navacchia A, Pianigiani S, et al. All-polyethylene tibial components generate higher stress and micromotions than metal-backed tibial components in total knee arthroplasty. Knee Surg Sports Traumatol Arthrosc. Epub 2015 May 10.

21. Nakamura T, Matsumine A, Uchida A, et al. Clinical outcomes of Kyocera Modular Limb Salvage system after resection of bone sarcoma of the distal part of the femur: the Japanese Musculoskeletal Oncology Group study. Int Orthop. 2014;38(4):825-830.

22. Tan PX, Yong BC, Wang J, et al. Analysis of the efficacy and prognosis of limb-salvage surgery for osteosarcoma around the knee. Eur J Surg Oncol. 2012;38(12):1171-1177.

23. Niimi R, Matsumine A, Hamaguchi T, Nakamura T, Uchida A, Sudo A. Prosthetic limb salvage surgery for bone and soft tissue tumors around the knee. Oncol Rep. 2012;28(6):1984-1990.

24. Pala E, Trovarelli G, Calabrò T, Angelini A, Abati CN, Ruggieri P. Survival of modern knee tumor megaprostheses: failures, functional results, and a comparative statistical analysis. Clin Orthop Relat Res. 2015; 473(3):891-899.

25. Holzer G, Windhager R, Kotz R. One-stage revision surgery for infected megaprostheses. J Bone Joint Surg Br. 1997;79(1):31-35.

26. Hardes J, Gebert C, Schwappach A, et al. Characteristics and outcome of infections associated with tumor endoprostheses. Arch Orthop Trauma Surg. 2006;126(5):289-296.

27. Gosheger G, Gebert C, Ahrens H, Streitbuerger A, Winkelmann W, Hardes J. Endoprosthetic reconstruction in 250 patients with sarcoma. Clin Orthop Relat Res. 2006;450:164-171.

28. McDonald DJ, Capanna R, Gherlinzoni F, et al. Influence of chemotherapy on perioperative complications in limb salvage surgery for bone tumours. Cancer. 1990;65(7):1509-1516.

29. Horowitz SM, Rapuano BP, Lane JM, Burstein AH. The interaction of the macrophage and the osteoblast in the pathophysiology of aseptic loosening of joint replacements. Calcif Tissue Int. 1994;54(4):320-324.

30. Young DR, Shih LY, Rock MG, Frassica FJ, Virolainen P, Chao EY. Effect of cisplatin chemotherapy on extracortical tissue formation in canine diaphyseal segmental replacement. J Orthop Res. 1997;15(5): 773-780.

31. Kienapfel H, Sprey C, Wilke A, Griss P. Implant fixation by bone in growth. J Arthroplasty. 1999;14(3):355-368.

32. Pai SK, Whitwell G, McMurray D, Stewart TD, Stone MH. Long-term results of a total knee prosthesis utilizing an all polyethylene tibial component. Arch Orthop Trauma Surg. 2013;133(8):1143-1148.

33. Grimer RJ, Taminiau AM, Cannon SR. Surgical outcomes in osteosarcoma. J Bone Joint Surg Br. 2002;84(3):395-400. 
OncoTargets and Therapy

\section{Publish your work in this journal}

OncoTargets and Therapy is an international, peer-reviewed, open access journal focusing on the pathological basis of all cancers, potential targets for therapy and treatment protocols employed to improve the management of cancer patients. The journal also focuses on the impact of management programs and new therapeutic agents and protocols on

patient perspectives such as quality of life, adherence and satisfaction. The manuscript management system is completely online and includes a very quick and fair peer-review system, which is all easy to use. Visit http://www.dovepress.com/testimonials.php to read real quotes from published authors.

Submit your manuscript here: http://www.dovepress.com/oncotargets-and-therapy-journal 